\title{
LOS DOS DISCURSOS DE MAQUIAVELO
}

LUIS VILLORO

INSTTIUTO DE INVESTIGACIONES FILOSÓFICAS

UNAM

En la historia de la filosofia política hay, al menos, un lugar común: Maquiavelo es el primer filósofo político moderno. Pero cuando se trata de explicar ese aserto, las interpretaciones se multiplican. Porque Maquiavelo, como Jano, presenta más de un rostro. Para los unos, su innovación es descubrir la autonomía de la política frente a la moral, revelar una racionalidad específica del campo político, sentando así las bases de una ciencia o, al menos, de una técnica del poder. Para los otros, su mérito es contrario: Maquiavelo habría establecido una nueva ética social, diferente de la medieval, acorde con el individualismo moderno. Ambas lecturas pueden fundarse en sus textos. La primera acude sobre todo a El Principe, la segunda, a los Discursos sobre la Primera Década de Tito Livio, pero una y otra pueden referirse a la totalidad de sus escritos. Porque su obra está atravesada por la tensión entre dos discursos, uno sobre el poder real, otro sobre el bien común. Si muchas interpretaciones de Maquiavelo no logran convencernos es porque se atienen sólo a uno de esos discursos, dejando en el desván el otro. La mayoría fluctúa entre dos extremos.

Si seguimos el discurso del poder, aparecerá el Maquiavelo tradicional, escándalo de moralistas, consejero de príncipes, guía de tiranos, preocupado sólo por señalar los artilugios del mantenimiento del poder. Unos apreciarán en él al fundador de un arte de la eficacia política, desembarazada de juicios de valor, otros lo denostarán como ejemplo de cinismo, pero cualquiera que sea el juicio que merezca, lo característico de su obra se verá en el abandono de una consideración ética en el pensamiento político.

Si seguimos, en cambio, el discurso del bien común, mostraremos el Maquiavelo patriota, republicano, deseoso de inculcar a sus conciudadanos una nueva moral capaz de restaurar el honor de la nación italiana. En sus límites, aparecerá el paladín de una nueva ética. Siguiendo uno u otro discurso podríamos llegar a ver la enseñanza de nuestro filósofo desde dos extremos cari- 
caturescos: como un "gangsterismo político"1 o, al contrario, como la "ética de un hombre nuevo".?

El hecho de que puedan darse ambas lecturas opuestas ino nos está indicando ya el carácter más distintivo de la obra de Maquiavelo: surgir de la tensión entre dos discursos en apariencia opuestos? En lugar de olvidar un lenguaje de Maquiavelo para sólo escuchar el otro ¿no valdría mejor comprender cada uno en función de su contrario? Pues el lenguaje esperanzado que anuncia un bien común para la nación italiana tal vez no sería pertinente sin el que intenta revelar los mecanismos efectivos del poder que permitirían realizarlo. A la inversa, el lenguaje sobre el poder efectivo carecería tal vez de objeto sin la propuesta de un valor superior que le otorgara un sentido. Que quizás la "modernidad" de Maquiavelo consista justamente en una intuición: la ciencia de la política provendría de la conjunción y tensión recíproca entre dos discursos diferentes, el del poder real y el del Estado bueno. Ensayemos esta lectura.

\section{El discurso del poder}

Maquiavelo nunca desarrolló una teoría acabada, ni siquiera propuso una concepción global del cuerpo político. ¿Por qué entonces puede considerársele uno de los fundadores de la ciencia política moderna? Quizás no porque expone una nueva teoría sino porque formula una nueva pregunta. Para el gobierno efectivo no importa tanto el Estado que debiera existir sino el que existe de becho. "Porque hay tanta distancia entre cómo viven los hombres y cómo deberían vivir, que quien abandona el estudio de lo que se hace para estudiar lo que debería hacerse, prepara más bien su ruina que su preservación. ${ }^{\not 3} \mathrm{La}$ pregunta de Maquiavelo es distinta a la de sus predecesores: interroga por los mecanismos que mantienen el poder efectivo. En el origen del poder no encuentra naturaleza ni razón, ni pactos entre iguales, en su origen encuentra un hecho descarnado: la fuerza.

Parte de una intuición certera: el Estado se basa en un acto de voluntad; un hombre o un grupo de hombres impone y mantiene un dominio sobre los otros: este acto convierte a un conjunto de individuos en un organismo político. De hecho, es el primero en emplear la expresión lo Stato para designar ese organismo. Entiende por él cautoridad, preminencia, poder político

1 Leo Strauss, Thoughts on Machiavelli, The Free Press, Glencoe, 1958.

2 F. de Sanctis, Storia della litteratura italiana, Bari, 1912. Para las diversas interpretaciones de la obra de Maquiavelo, véase Claude Lefort, Le travail de l'auvre. Machiavel, Gallimard, París, 1972.

3 Il Principe, A. Mondadori ed., Italia, 1950, p. 69, en lo sucesivo citaremos $P$. 
[...] que se ejerce sobre un determinado agrupamiento de hombres”. ${ }^{4} \mathrm{El}$ fundamento del Estado no habrá que buscarlo en la economía divina, ni en la naturaleza, ni en algún convenio entre los hombres. Estriba en un acto de poder.

Pero ese acto no es arbitrario, responde a una necesidad. Ante la multiplicidad de los intereses particulares en pugna (que, en el caso de Italia, la habían llevado al deshonor y al caos) es necesaria una fuerza superior que los limite y encauce hacia un fin común. El poder político cumple una función: imponer el interés general sobre los deseos insaciables de los hombres. Las facciones sólo pueden cesar su pugna destructora y encontrar satisfacción parcial en el interés general del Estado. Por ello, en la situación italiana, el príncipe encarna la voluntad general. No porque haya sido designado para representarla sino porque, por el hecho mismo de su dominio, la realiza. El "príncipe" podría, en teoría, ser un hombre o varios, aunque en la Italia renacentista sólo la primera posibilidad sea realista. Lo que lo distingue es que encarna el poder general del Estado; en él la voluntad personal coincide con la colectiva. El príncipe es - dice Gramsci- "un condotiero que representa plástica y antropomórficamente el símbolo de la voluntad colectiva". 5 La representa no en idea sino en la realidad concreta. Impone su voluntad, es cierto, por la fuerza, pero sobre todo por su virtui.

Virtú no tiene aquí un significado moral; significa impulso libre, energía, valor, denuedo, capacidad para las grandes hazañas. A ella se opone la fortuna. Fortuna es un concepto vago, al que puede acudirse cuando no tenemos una explicación racional de un acontecimiento. Se refiere a las fuerzas ciegas, irracionales, que no dependen de la libertad individual. La historia resulta del juego entre virtí y fortuna, es decir, entre las fuerzas reales que rebasan la voluntad del individuo y el denuedo de éste por conocerlas y aprovecharlas. Maquiavelo compara la fortuna con

un río fatal que, cuando se embravece, inunda las llanuras, echa a tierra los árboles y edificios, quita el terreno de un paraje para llevarle a otro. Cada uno huye a su vista, todos ceden a su furia sin poder resistirla. Sin embargo, por más formidable que sea su naturaleza, no por ello sucede menos que los hombres, cuando están serenos los temporales, pueden tomar precauciones, haciendo diques y explanadas; de modo que cuando crezca de nuevo esté forzado a ir por un canal o que su ímpetu no sea tan licencioso ni dańino. Sucede lo mismo con la fortuna; la cual muestra su poder cuando no encuentra una pirtí que le resista, y vuelve su impetu hacia la parte en que sabe que no hay diques ni otras defensas capaces de detenerla. ${ }^{6}$

4 F. Chabod, Lidea de nazioni, cit. por A. Córdoba, Sociedad y Estado en el mundo moderno, UNAM, México, 1973, p. 67.

5 A. Gramsci, Note sul Machiavelli, Einaudi, Turín, 1949, p. 3.

$6 P$, cap. XXV, p. 97. 
En este capítulo de El Principe concede que la fortuna puede ser "el árbitro de la mitad de nuestras acciones", en los Discursos, en cambio, sostiene que a la verdadera virtú nada puede resistirla. "Se puede establecer que la Fortuna es inválida y debilísima para arrebatar nuestra más pequeña virtú. Y conviene no dudar que nada de lo que buscas y amas te es tan fácil de obtener como la virtú. Sólo carece de virtú quien no la quiere. ${ }^{77}$ La libre voluntad política, con denuedo, señala su curso a la historia.

El arte del político consiste justamente en comprender y utilizar para su propio poder las fuerzas ciegas de la fortuna. Reducidos a este género de discurso, el conocimiento político no se expresa en términos de valores, como la justicia, el orden o la paz sociales; se refiere, más bien, a los obstáculos que se levantan ante el poder y los medios para evitarlos. La política es el estudio de los medios para lograr y mantener el poder. Pertenecen a otro género de discurso la "bondad" o "maldad" moral de los actos, a éste le importan, en cambio, su utilidad o eficacia. De allí el “inmoralismo" del discurso que lo expresa.

$\mathrm{Al}$ arte del buen gobierno no le concierne la bondad o maldad de las intenciones del príncipe sino sólo la eficacia de sus acciones. La hipocresía, la adulación, el engaño o la violencia pueden ser manchas en un alma bella, pero serán virtudes políticas en la medida en que consoliden los fines del Estado. Lo que se considera es el fin, no importan los medios que se usen. ${ }^{8}$ Mejor, sin duda, si esos medios son conformes a la moral y a la religión, pero si no lo fueren, no hay razón politica para dejar de emplearlos.

Un príncipe, sobre todo uno nuevo, no puede observar en todo lo que hace tener por virtuosos a los hombres; para mantener el estado, a menudo está en la precisión de obrar contra la fe, contra la caridad, contra la humanidad, contra la religión. Pero es menester que su ánimo esté dispuesto a volverse según que los vientos y variaciones de la fortuna le ordenen y, como lo he dicho más arriba, a no apartarse del bien mientras lo pueda, pero a saber entrar en el mal cuando le sea necesario. ${ }^{9}$

El fin de la política es el poder; sus condiciones, la utilización de las fuerzas de la fortuna por la virtú del gobernante.

Puestos el fin y las condiciones, se establece entre ellos una necesidad racional. La política no puede ir contra la necesidad, debe comprenderla y utilizarla. En la cadena necesaria entre medios y fines puede entrar el mal moral. Porque también el mal es, a menudo, un eslabón necesario en la cadena. La

7 Discorsi supra la Prima Decada di Tito Livio, Opere, G. Salerno ed., Milán, 1968, en lo sucesivo, citaremos $D$.

8 , cap. XVII, p. 76-77.

${ }^{9} P$, cap. XVIII, p. 76. 
astucia del gobernante consistirá justamente en convertir en mérito propio los actos que se realizan por necesidad. "Los hombres prudentes saben siempre convertir en mérito propio sus acciones, aunque sea la necesidad la que los constriña. ${ }^{10}$ Quien sabe apreciar los medios necesarios a la acción política y los pone en práctica, no es por ello bueno o malo moralmente, es racional, porque obra acertadamente para lograr el fin que quiere. El Príncipe abunda en ejemplos de actos moralmente condenables que son racionales en ese sentido. Maquiavelo, por ello, los llama a veces "buenos", aunque el adjetivo no puede tener aquí una connotación moral. La violencia, por ejemplo, es inevitable en política, luego, hay que usarla con oportunidad. El castigo debe ejercerse a tiempo para obtener el resultado apetecido, como lo hizo César Borgia en la Romaña. La crueldad puede hacer bien al Estado, porque restablece la paz y la concordia. ${ }^{11}$ Los asesinatos de Rómulo parecen malos sólo si no se considera su fin. ${ }^{12}$ Porque censurable es la violencia que destruye, no la que construye. ${ }^{13}$ La hipocresía, el engaño, son perversos moralmente, pero pueden ser "buenos" políticamente. Porque no entra en la cuenta la intención sino la dimensión social de los actos y su resultado efectivo en una relación de poder. Importa la imagen que el pueblo tiene del príncipe, cómo se deja ver, no lo que sea en su subjetividad. No interesa que sea justo sino que lo parezca ante los demás; no es pertinente que sea, en realidad, humanitario o fuerte sino que así lo crea el pueblo. La biena intención puede llevar a perder el Estado, la correcta apariencia, aun engañosa, puede salvarlo. "Porque todos los hombres se sienten tan satisfechos con lo que parece como con lo que es; así, muchas veces se mueven más por las cosas que aparecen que por las que son. ${ }^{\text {} 14}$ Por otra parte, importa más, en último término, ser temido por lo que se representa que ser amado por lo que se es. ${ }^{15}$

El conocimiento político tiene por objeto comprender la cadena de actos necesarios para lograr un fin: el poder. Versa sobre las fuerzas reales que se oponen al acto libre y sobre los antecedentes y consecuencias de la acción en una comunidad política. Notemos que este conocimiento no implica la elaboración de una teoría, ni siquiera conduce a principios generales. Por ello no constituye, en sentido estricto, una ciencia. En realidad, los conocimientos que transmite Maquiavelo a sus contemporáneos tienen por fuente la experiencia personal de la vida pública, su propia práctica política y diplomática, los testimonios ajenos transmitidos por la historia, cierta sabiduría derivada

${ }^{10} \mathrm{D}$, lib. I, cap. LI, p. 200.

$"$ Cfr. P, cap. XVII, p. 72.

${ }^{12} D$, lib. I, cap. IX, p. 120

13 Ibid.

$14 D$, lib. I, cap. XXV, p. 154.

15 Cfr: $P$, cap. XVII, p. 73. 
del trato con los hombres. No se trata de un saber teórico, comprobable objetivamente, como el de la ciencia, sino de un conocimiento personal, precientífico, destinado a orientar la acción; ${ }^{16}$ su objeto es la relación de medios a fines en el comportamiento político.

Por supuesto que ese conocimiento personal puede expresarse en generalizaciones válidas y eventualmente podría codificarse en reglas de acción. Proposiciones de este género no faltan en la obra de Maquiavelo. El objeto de ese conocimiento sería justamente establecer ligas causales entre medios y fines de las acciones, en condiciones dadas. Luego, es un conocimiento que conduce a una técnica. La política, en Maquiavelo, no es una ciencia, es una técnica del poder. "El Principe no es un libro moral o inmoral -escribe Cassirer- es simplemente un libro de técnica política. ${ }^{\$ 17} \mathrm{La}$ técnica no es, en sí misma, justa o injusta; puede ser útil para cualquier fin. Su criterio no es el bien o el mal morales sino la eficacia. Obedece a una forma específica de racionalidad: la que no se pregunta por el fin más razonable a seguir sino por los medios conducentes a lograrlo. Es una racionalidad instrumental. Dados un fin y las condiciones de la acción, determina los medios más adecuados en esas condiciones.

En Maquiavelo encontramos pues un primer discurso político. No versa sobre la sociedad deseada sino sobre la sociedad real. No comprende juicios de valor sino juicios de hecho. No indaga sobre la validez del fin de la acción política sino sobre los instrumentos para lograrlo. Es un discurso de la necesidad, no de la libertad. Le corresponde una forma de ejercicio de la razón: la razón técnica o instrumental. La razón técnica da por supuesto el fin elegido y revela el sentido de los actos en relación con ese fin. El sentido de esos actos es pues "extrínseco" a ellos: está determinado por su adecuación al fin elegido. Pero si los actos políticos reciben un sentido por el fin elegido ino cabe también preguntar por el sentido de ese fin? Esa pregunta ya no corresponde al mismo juego de lenguaje ni obedece a la misma forma de racionalidad. Porque no se refiere a los medios necesarios, sino a la bondad del fin que les otorga un sentido. Ese segundo lenguaje está mezclado con el anterior en los escritos de Maquiavelo. Tratemos ahora de identificarlo.

\section{El discurso del bien comin}

Si en El Principe predomina el lenguaje del poder, en los Discursos Maquiavelo se preocupa por restaurar en Italia las virtudes que hicieron la grandeza del pueblo romano. Ante la división, la servidumbre y la corrupción que anegan a Italia, es menester restaurar la fe en un destino común, capaz de superar los

16 Sobre la distinción entre saber objetivo y conocimiento personal puede verse: Villoro, Creer, saber, conocer, Siglo XXI, México, 1982, caps. 9 y 10.

17 E. Cassirer, El mito del Estado, FCE, México. 
mezquinos intereses particulares y devolver el honor y la dignidad al pueblo italiano. Pero en Italia no hay un principio tradicional de autoridad que revista, a los ojos del pueblo, la majestad y la gloria de la nación, no existe el equivalente de la monarquía francesa, por ejemplo. A falta de poder acudir a la continuidad de una tradición, Maquiavelo vuelve los ojos al recuerdo de un pasado glorioso: la república romana. No se trata de un regreso sino de la propuesta de un renacimiento. El tema de la grandeza de un pueblo lleva a preguntarnos por la forma de Estado mejor. Será, responde Maquiavelo, el que realice el bien común. "Pues no es el bien particular sino el bien común el que hace grandes a las ciudades." "Y, sin duda, ese bien común —continúano se observa más que en las Repúblicas. ${ }^{18}$ Entonces, ya no preguntamos por el Estado existente de hecho, sino por el más valioso.

En todo Estado siempre hay dos partidos: el de los nobles y el del pueblo. De su lucha nace la agitación, el desorden, el conflicto permanentes. El desacuerdo sólo tiene una alternativa: las leyes, que regulan las relaciones entre las clases opuestas. ${ }^{19}$ En una sociedad no corrompida, el poder del pueblo ofrece la mejor vía. Él es el mejor garante de la libertad. ${ }^{20} \mathrm{El}$ pueblo servirá de control a un poder excesivo, frenará las ambiciones de los nobles y pondrá límites a las dictaduras. ${ }^{21}$ Maquiavelo compara el gobierno del pueblo con el de un príncipe sin control y se inclina por el primero. El pueblo es más prudente en sus elecciones, más amante de la libertad, menos víctima de las pasiones, porque no desea mandar sino tener libertad y seguridad. ${ }^{22}$ Pero el pueblo no puede tener libertad en todo. "Un pueblo que puede hacer lo que quiere no es sabio.”23 Una multitud sin cabeza es, en efecto, inútil. El pueblo necesita siempre un guía que le muestre su auténtico bien y lo libre de engaños. ${ }^{24}$ De la libertad absoluta del pueblo puede seguirse la tiranía. Causas de la mayor parte de las tiranías son "el excesivo deseo de ser libre del pueblo y el excesivo deseo de dominar de los nobles ${ }^{25}$ Los poderosos buscan el poder absoluto para oprimir al pueblo, pero éste, al buscar su liberación, lleva al poder a un jefe popular o a un grupo que pronto se convierte en tirano del propio pueblo. ${ }^{26}$

¿Cuál sería entonces el mejor gobierno? Maquiavelo no se hace ilusiones sobre la bondad de ninguna de sus formas. Las formas clásicas de gobierno se

${ }^{18} D$, lib. II, cap. II, p. 235.

${ }^{19} D$, lib. I, cap. IV, p. 105.

${ }^{20} D$, lib. I, cap. V, p. 107.

${ }^{21} D$, lib. I, cap. XXXVIII, p. 123.

${ }^{22} C$ fr. $D$, lib. 1 , cap. LVIII.

${ }^{23} D$, lib. I, cap. LVIII, p. 217.

${ }^{24} D$, lib. I, cap. XILIV y LIII.

${ }^{25} D$, lib. I, cap. XI, p. 184.

26

Ibid. 
transforman fácilmente en sus versiones corruptas: la monarquía en tiranía, la aristocracia en oligarquía, la democracia en licencia. ${ }^{27} \mathrm{Se}$ inclina pues por una solución de equilibrio: régimen mixto, con instituciones representativas de las dos clases, el pueblo y los nobles. ${ }^{28}$ Sería un sistema duradero en la medida en que se controlara la ambición de los poderosos con el poder del pueblo, y la inclinación al desorden de éste con la autoridad de la nobleza. Superando la discordia, se lograría imponer un "bien común" a las distintas clases. Ejemplos no faltan: los reyes de Esparta lograron un Estado firme y duradero porque pudieron unir en el mismo propósito nobleza y plebe, Roma tuvo un gobierno feliz durante la república, porque acertó a equilibrar el poder del senado con el de los representantes del pueblo. En la época de Maquiavelo, Venecia es la que más se acercaría a esos modelos antiguos.

Ahora bien, sobre la base de ese sistema equilibrado de gobierno, siempre es preferible la república a la dictadura o al principado, porque, en la república, el pueblo tiene más poder para proteger la libertad contra las ambiciones de los poderosos. República buena es la que busca, en la paz y en el orden, sin caer en la discordia, preservar la libertad en el interior y el poder de la nación ante las demás. Sólo alcanzan la grandeza los pueblos libres; se pierden cuando se vuelven esclavos. Ésta es la lección de la historia de Roma que Maquiavelo propone a los italianos, con la esperanza de incitarlos a la libertad.

Las reflexiones sobre el bien común y el gobierno "mejor" se basan en un supuesto que no puede ser objeto de ciencia: es preferible una sociedad que cumpla con ciertos valores. Estos valores están implícitos en el discurso de Maquiavelo, no están expresados paladinamente. Tenemos que descubrirlos entre líneas. Ante todo es el orden, la concordia duradera en la sociedad. Hay que acabar con los conflictos que desgarran a la nación. Sería ésta la condición de posibilidad del Estado mismo. Pero la concordia está al servicio de la libertad y de la gloria. Maquiavelo no dice con claridad qué entiende por esos conceptos, pero su significado se desprende del uso que hace de ellos. Libertad es, en lo interior, lo contrario de la opresión de los ciudadanos por un tirano o por los nobles; autonomía frente al exterior. Gloria es algo más vago, que despierta la pasión y enciende la esperanza. Comprende, quizás, la realización colectiva de la virtú, el dominio sobre los otros pueblos, la civilización, la realización de empresas osadas por una nación, en suma, todo lo que de manera intuitiva atribuimos a la "grandeza" de un pueblo, como Roma o Esparta. Cuando Maquiavelo habla del "bien común" supone que consiste en la realización de esos valores por la nación. Pero esos valores no se realizan en la sociedad italiana, corresponden a una sociedad otra, objeto de

$27 D$, lib. I, cap. II, p. 99.

28 Ibid. 
fe, esperanza, proyecto para dirigir nuestra acción y encender nuestro ánimo, sociedad deseada que se contrapone a la sociedad real.

¿Por qué preferir esa sociedad y no otra? ¿Por qué esos valores (concordia, libertad, gloria) y no otros? No hay una justificación explícita. La proyección de los valores deseables para la sociedad italiana proviene de un conocimiento personal, intuitivo, del diagnóstico de los males de la época y de la admiración por las repúblicas gloriosas del pasado. Nada tiene que ver con una "ciencia" de la política, ni aun con una "técnica" del poder. Los valores que proyectamos son objeto de pasión.

El Principe termina con una exhortación a la realización de la grandeza italiana. El último capítulo, el XXVI, no parece derivarse de los anteriores, por ello ha sumido en perplejidad a muchos comentadores. Mientras los capítulos anteriores desarrollan una técnica del poder, el último propone un fin a la gente italiana. El ideal a seguir es la constitución de una nación, la unión de Italia frente al dominio extranjero y la restauración de la pirtú y del valor italianos. Termina con una cita de Petrarca: 'La virtú contra el furor tomará las armas; y el combate será corto, que el antiguo valor aún no ha muerto en el corazón italiano. ${ }^{29}$ El lenguaje de la pasión, de la fe y de la esperanza, irrumpe en el último capítulo y deja a un lado los fríos análisis sobre las relaciones reales de poder. Como indica Chabod: "El último capítulo de $E l$ Principe es el desenfreno de la pasión mal contenida que, trazados los contornos lógicos, los traspone, en un nuevo momento creativo, en el ímpetu de su deseo y los convierte en esperanza y fe tras haberlos contemplado como razón y posibilidad. .30 $^{\text {20 }}$

No es que el último capítulo carezca de relación con los anteriores. Chabod hace notar, con acierto, que la posibilidad de reconstruir el Estado, por obra del príncipe, tema de los capítulos anteriores, suponía, en la circunstancias italianas, un elemento de fe y esperanza que se añadiría a la necesidad política estricta. ${ }^{31}$ Pero, justamente, ese lenguaje de fe y de esperanza no se deduce lógicamente del cálculo sobre los medios para conservar el poder, añade a éste la propuesta de un fin valioso por sí mismo.

Estamos pues ante dos discursos diferentes. En el primero (presente, sobre todo, en El Principe, hasta el capírulo XXV) Maquiavelo habla de los factores que favorecen u obstaculizan el poder real. Trata sobre todo de las relaciones entre los medios que han de emplearse para lograr los fines del Estado. Está constituido por enunciados de hechos, que describen relaciones necesarias entre ellos, condicionadas a los fines elegidos. Es un lenguaje de la necesidad. El segundo discurso (presente, sobre todo, en los Discorsi y en el último capítulo

${ }^{29} P$, cap. XXVI, p. 102.

30 F. Chabod, Escritos sobre Maquiavelo, FCE, México, 1984, p. 78.

31 Itid., p. 32. 
de El Principe) trata principalmente de la sociedad deseable y de los fines a clegir para la nación. Está constituido por enunciados de valor, descripciones de la sociedad buena y enunciados preceptivos que inducen a perseguir esos valores. Apela a la libre elección de un Estado bueno para Italia. Es un lenguaje de libertad.

Uno y otro discurso responden a formas diferentes de racionalidad. Frente a una racionalidad instrumental propia de una técnica del poder, que se preocupa por determinar los medios más eficaces para lograr un fin, cabe hablar de una racionalidad en la elección de los fines mismos, que intenta proponer la forma de sociedad mejor.

Un lenguaje no se deriva lógicamente del otro. Del conocimiento de los mecanismos para mantener el poder no se puede concluir cuál será el Estado cuya elección sería más razonable para el bien común. Del conocimiento del mejor Estado no se deduce cuáles son los mecanismos más efectivos para lograrlo.

Maquiavelo no se preocupa de la separación entre uno y otro discurso, el problema de establecer una derivación lógica entre ellos le es ajeno. Lo importante para nosostros es que, en su obra, se pone de manifiesto que ambos lenguajes son imprescindibles en el conocimiento de la polírica, más aún, que el discurso político supone la unión de ambos. La obra de Maquiavelo nos da indicaciones también de la dirección en que podríamos encontrar la relación entre los dos lenguajes. Sin volverlo más coherente de lo que fue, busquemos esa relación a partir de sus escritos.

\section{La mediación entre los dos discursos}

Maquiavelo es pesimista acerca de la naturaleza humana. 'Los hombres - piensa - son más inclinados al mal que al bien. ${ }^{\$ 32}$ No basta, por lo tanto, saber cuál es el mejor gobierno y proponerlo, pues "los hombres no obran nunca bien si no es por necesidad, pero donde se puede elegir y hay libertad de acción se llena todo, inmediatamente, de confusión y de desorden" ${ }^{33}$ Para alcanzar el bien hay que comprender cuál es la necesidad que compele a él. Son las circunstancias ajenas a la voluntad humana - la "fortuna" - las que a menudo determinan si se realiza o no el bien querido. Por ejemplo, si Atenas, bajo Pisístrato, no logra la libertad, a diferencia de Roma bajo la república, no se debe a que la primera no la quisiera y la segunda sí. "Quien considere todo lo dicho - escribe Maquiavelo- no criticará a Atenas ni ensalzará a Roma, sino que culpará tan sólo a la necesidad por la diversidad de accidentes que sucedieron en las dos ciudades. ${ }^{34}$ Así, para lograr el mismo fin, lo

${ }^{32} D$, lib. I, cap. IX, p. 121.

33 , lib. I, cap. III, p. 104.

${ }^{34} D$, lib. I, cap. XXVIII, p. 158. 
que se prescribe para una situación debe ser distinto a lo requerido para otra. "Porque se deben instituir diferentes órdenes y modos de vida para un sujeto malo y para uno bueno, pues no puede haber la misma forma en materias en todo contrarias. ${ }^{35}$ En suma, el Estado deseable en abstracto, al considerar las circunstancias concretas, deberá acoplarse a la necesidad si quiere realizarse.

La reflexión anterior nos permite explicar la aparente contradicción en el pensamiento de Maquiavelo. ¿'Por qué, si considera la república como la mejor forma de gobierno, propone a su patria el principado? ¿Por qué, al buscar la libertad como valor superior, desarrolla una técnica de la dominación?

La república es excelente para un pueblo que no ha caído en la corrupción. Era el caso, según nuestro autor, de Roma. Pero un pueblo corrompido no es capaz de realizarla: "Porque un pueblo donde por todas partes ha penetrado la corrupción no puede vivir libre, no ya un breve lapso de tiempo sino ni un momento. $\$ 36$ Por otra parte, donde existe igualdad no se puede establecer un principado y donde no la hay no se puede establecer una república. ${ }^{37}$ Este último es el caso de Italia y, en particular, de Florencia. En Florencia reina la desigualdad y la corrupción. Los reformadores "nunca han buscado la utilidad común, sino sus propios intereses, lo que ha producido, no un nuevo orden, sino un mayor desorden". ${ }^{38}$ De allí la necesidad en una ciudad corrupta, de un príncipe que guíe al pueblo, tome sobre sí el interés general y lo imponga sobre los particulares. ${ }^{39}$ El principado no es el gobierno mejor pero es la manera efectiva de ordenar de nuevo una república en situación de conflicto entre intereses particulares. Cumple la función que, de hecho, ha tenido la monarquía en Francia, España o Inglaterra. El Estado nace, de hecho, de la fuerza. La violencia del príncipe cumple una función necesaria: establecer el orden y la ley. Ante la necesidad primordial de fundar el Estado, la distinción entre república y principado pasa a segundo término. ${ }^{40}$

El mejor gobierno sería una república libre de tiranía y bajo el control del pueblo. Ese ideal se basa en una elección. Se expresa en un lenguaje valorativo, sobre la sociedad deseable. Pero el hombre es fundamentalmente egoísta y se gíua por su interés particular. La elección del valor choca con la necesidad. Si la elección de la sociedad deseable quiere relizarse, debe acoplarse a la necesidad señalada por las circunstancias. La libertad para ser eficaz debe doblegarse a la necesidad. Una frase podría resumir el arte de la política para Maquiavelo: "Una República o un Principado debe aparentar hacer libremente aquello a

${ }^{36} D$, lib. I. cap. XVI, p. 138.

${ }^{37} D$, lib. I, cap. LV, p. 210.

$38 D$, lib. I, cap. XILIX, p. 197.

${ }^{39}$ Cfr. $D$, lib. I, cap. LV.

40 Tal como observa Chabod, op. cit., p. 403. 
que le obliga la necesidad. ${ }^{\$ 41}$ La acción política consiste en la elección libre de una necesidad.

\section{¿Hacia una moral politica?}

Al pretender realizar el proyecto elegido, conforme al "bien común”, la necesidad impone realizar actos que la moral aceptada consideraría "malos". Es necesario ejercer la violencia para obtener la concordia. Pero entonces acciones "malas" moralmente, como el asesinato de los enemigos, el engaño o la crueldad, pueden considerarse "buenas" al juzgarse medios necesarios para lograr un fin bueno. Si el príncipe expresa la "voluntad general", todos los medios que conduzcan a afianzar su poder serán necesarios para realizar esa voluntad. En la medida en que son necesarios, podrían ser considerados "buenos". Sin que Maquiavelo lo diga, podemos concluir que esos actos se juzgarían "buenos" conforme a un tipo de moral distinta a la individual. Llamémosla provisionalmente "moral política". ${ }^{42}$ Maquiavelo no formula esa "moral política", es dudoso incluso que hubiera aceptado el término. Pero está implícita en su manera de juzgar ciertos actos como "malos" moralmente y "buenos" o "excusables" en consideración a su fin político. Habría muchos ejemplos de esa ambigüedad. Se refiere a los crímenes de Rómulo. Rómulo mata a su hermano Remo y consiente en la muerte de su colega Tito Tacio. Pero lo hace por el "bien común", porque lo juzga necesario. Así lo demuestra el hecho de que no establece un gobierno tiránico sino un senado que rija la ciudad. Maquiavelo no oculta que considera el asesinato malo en sí, pero justifica a Rómulo por haber hecho lo necesario para el bien común. El mismo acto no es malo, conforme a su fin político. "Considerando pues todas estas cosas, concluyo que para organizar una república es necesario estar solo, y Rómulo merece excusa y no reproche por la muerte de Remo y Tito Tacio. $\$ 43$

Otro caso: en política, cuando no es posible interferir en el mal, es preferible no intentar detenerlo. "Se deben considerar bien las fuerzas del mal y, si te parece que tienes bastante poder para sanarlo, ponerte a ello sin demora; en otro caso, dejarlo estar, sin intentar nada en contra. ${ }^{\text {} 44}$

En consecuencia, un mismo acto (por ejemplo, un asesinato) puede ser considerado "malo" conforme a la moral individual y "bueno" conforme a una "moral política". Lo cual plantearía el problema de la relación entre ambas morales. ¿Cuáles serían los criterios para hacer prevalecer un juicio sobre el otro? ¿Hasta dónde el juicio de una "moral política” podría privar sobre el

41 , lib. I, cap.. LI, p. 200.

42 Podriamos ver en ella un antecedente lejano de la "moral de la responsabilidad" de Max Weber.

43 , lib. I, cap. IX, p. 122.

44 , lib. I, cap. XXXIII, p. 168. 
juicio de una moral individual? :O se trata de niveles de juicio irreductibles entre sí y contradictorios? Maquiavelo no responde a estas preguntas. Ni siquiera se las plantea. Pero en su pensamiento podemos encontrar algunas indicaciones sobre la manera de abordar el problema que hubiera podido ser la suya.

1. En primer lugar, no disiparía la ambigüedad de juicio. Respecto de un mismo acto, pueden subsistir dos juicios contrarios. El caso de Agátocles, pretor de Siracusa, evocado en el capítulo VIII de El Principe, es paradigmático. La defensa exitosa de su ciudad frente a los cartagineses no puede atribuirse a la fortuna sino a su virtú. "Si consideramos el valor de Agátocles en el modo en que arrostra los peligros y sale de ellos y la sublimidad de su ánimo en soportar y vencer los sucesos que le son adversos, no vemos por qué le tendríamos por inferior al mayor campeón de cualquier especie." Cumple Agátocles con la imagen del jefe que vence con su virtud a la fortuna y logra la salvación de su patria. Sin embargo, frente a ese juicio laudatorio, subsiste otro que lo condena: "La matanza de sus conciudadanos, la traición de sus amigos, su absoluta falta de fe, de humanidad y de religión, son ciertamente medios con los que uno puede adquirir el imperio, pero no adquiere nunca con ellos ninguna gloria." Sus actos "no permiten alabarle como si él mereciera ocupar un lugar entre los hombres insignes más eminentes". ${ }^{55}$ ¿Por qué no es merecedor de gloria ni alabanza? No ciertamente porque haya sido un príncipe débil o ineficaz en lograr el bien común de Siracusa; antes al contrario, utilizó en esa empresa, con arrojo, los mismos medios que Maquiavelo recomienda al príncipe para mantener el poder. Pero no merece gloria porque sus actos son susceptibles de una condenación moral. ¿Debió entonces Agátocles renunciar al poder que conquistó sin gloria? ¿Qué es preferible, en ese caso: salvar a la ciudad a costa de la propia ignominia o suscitar la alabanza por sacrificar a la virtud el poder? Maquiavelo no decide, acepta los dos juicios.

2. De algunos ejemplos de Maquiavelo podríamos deducir ciertos criterios para juzgar la bondad de una acción según lo que hemos llamado "moral política". Admite Maquiavelo que puede haber un "buen" o un "mal" uso de la crueldad. "Podemos llamar buen uso de los actos de crueldad, si empero es lícito hablar bien del mal, que se ejercen de una vez, únicamente por la necesidad de proveer a su propia seguridad, sin continuarlos después, y que al mismo tiempo trata uno de dirigirlos, cuanto es posible, hacia la mayor utilidad de los gobernados. $\${ }^{26}$ Podríamos generalizar este acto en la siguiente forma: una acción "mala" conforme a la moral individual puede considerarse "buena" según la moral política si y sólo si: a) es dirigida hacia un fin bueno (la "utilidad de los gobernados"); b) es un medio necesario para la obtención

$45 P$, cap. VIII, p. 50.

46 $P$, cap. VIII, p. 52. 
de ese fin y c) se reduce a producir ese resultado, es decir, no se acompaña de actos superfluos que rebasen los estrictamente necesarios para lograr el fin. El político tiene, por lo tanto, que estar seguro de la necesidad de esa acción y relizarla en la medida sólo en que sea necesaria. De allí que requiera de una técnica del poder. Pero la utilización de ese criterio no elimina la dualidad del juicio. La acción cruel podrá ser juzgada "buena” conforme a un criterio político, pero sigue ocultando un mal moral. La ambigüedad del juicio de Maquiavelo se expresa en esta frase dubitativa: "si sin embargo es lícito hablar bien del mal".

3. La acción política es, a la vez, búsqueda del bien común, expresado en la ley, y obra de la fuerza. El político tiene parte de hombre y parte de bestia.

Debéis pues saber que hay dos modos de combatir: el uno con las leyes, el otro con la fuerza. El primero es propio del hombre, el segundo de las bestias: pero como a veces el primero no basta, conviene recurrir al segundo. Le es pues necesario a un príncipe saber hacer buen uso de la bestia y del hombre. Esto es lo que con palabras encubiertas enseñaron los antiguos autores a los príncipes, cuando escribieron que muchos de la antigüedad, como Aquiles, fueron confiados en su nińez al centauro Chirón, para que los criara y educara bajo su disciplina. Lo cual no quiere decir otra cosa sino que tuvieron por preceptor a un maestro mitad bestia y mitad hombre; es decir, que un príncipe tiene necesidad de saber usar de una y otra naturaleza, y que la una sin la otra no sería duradera. ${ }^{47}$

Para juzgar cuándo es oportuno usar de una u otra naturaleza, el príncipe requiere de una virtud esencial al gobierno: la prudencia. Ésta consiste en saber emplear, en cada contexto concreto, los medios adecuados, dosificándolos según las circunstancias. El conocimiento político sería para Maquiavelo, antes que una ciencia, un conocimiento personal, dirigido a situaciones concretas. Pero Maquiavelo no desarrolla ninguna teoría sobre las formas de sabiduría política ni tampoco sobre los criterios que regirían en una moral política. Ha abierto las puertas a un campo sin recorrerlo. 